\title{
CGMW: A GLOBAL GEOLOGICAL NETWORK
}

by

Frances Delany

\begin{abstract}
Mapping is a traditional tool for geologists, but the plotting of results from modern observation techniques, imaginatively conceived legends and the latest printing techniques can produce a great variety of syntheses that are a far cry from early geological maps. The role of the Commission for the Geological Map of the World (CGMW) is to coordinate international cooperation in the world-wide compilation of small scale map syntheses in the earth sciences and to promote geoscientific mapping on a national level.
\end{abstract}

From a small group of European geologists officially constituted during the 1881 International Geological Congress in Bologna to propose a standard legend and draft a geological map of Europe, the Commission for the Geological Map of the World (CGMW) has evolved into a world-wide network of cooperating geological surveys. It has contributed to progress in the earth sciences by preparing and printing maps, recognizing that these maps provide the geometric constraints for data syntheses and can, through imaginative and novel legends, demonstrate the relationship between heterogenous parameters.

The original Bologna group was enlarged to comprise representatives of all the Geological Surveys of Europe, thus forming the Commission for the Geological Map of Europe which still retains a certain autonomy within the framework of CGMW. In 1910, at the eleventh session of the International Geological Congress, when the first edition of the Geological Map of Europe was nearly ready for printing, a 1:1 000000 Geological Map of the World was proposed. In view of the size of such a task, and the lack of a base map, it was decided that a world map be drafted to a 'suitable scale' according to the legend used for the Geological Map of Europe. Representatives of all countries were invited to collaborate and thus the Commission for the Geological Map of the World came into being.

\section{Organization}

Today, statutory members are the geological surveys or national organizations responsible for geological mapping and CGMW membership includes all territories or countries of the

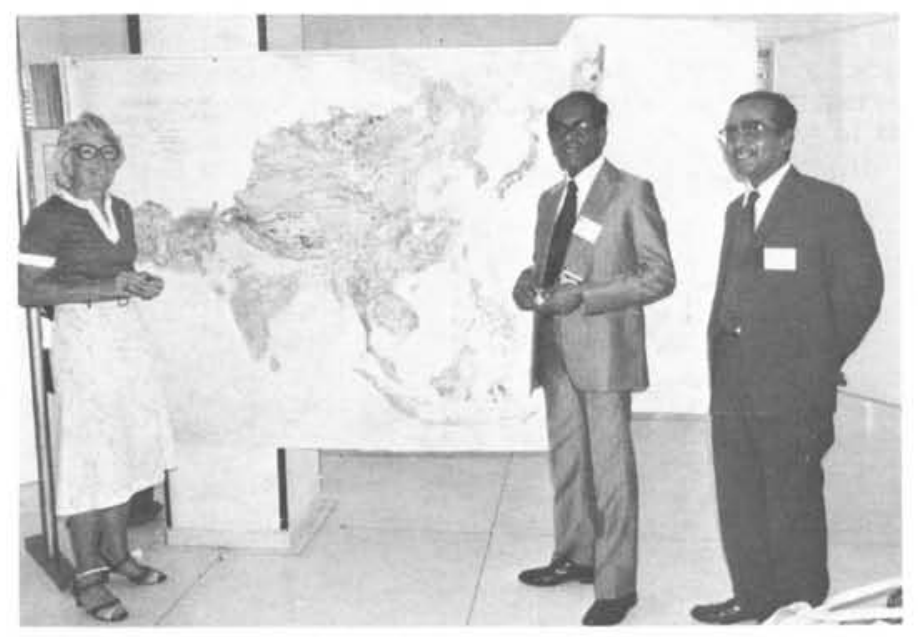

Displaying the Geological Map of South and East Asia at III GEOSEA in Bangkok, Thailand last November are, left to right, Frances Delany, Secretary General of CGMW, T.K. Kurien (India) and D.K. Ray (India). world. Cooperation is not limited to survey members; frequently the necessary expertise for thematic maps is sought in universities or other academic or commercial organizations. Geologists employed in industry formerly expressed their interest in CGMW activities by attending CGMW plenary assemblies, but participation was formalized in 1972 by the creation of associate memberships, open to all organizations with geological interests. Members attend all CGMW functions, preview the maps that are exhibited in draft form, and are encouraged to provide a return flow of information.

The compilation of small scale maps normally covers a continent or a major region of the earth. The geological surveys of the region are grouped together under a CGMW Subcommission headed by a Vice-President who is traditionally a member of the organization responsible for compiling the continental geological map.

Whenever possible, CGMW insists that the participating country nominate a national coordinator. These coordinators constitute the Editorial Committees. The Convenors of Editorial Committees are normally also from the region. They, in a sense, play a primordial role: too conservative, they can readily prevent the map from presenting modern information; too avant-garde, they may be carried away by theoretical considerations and forget that a map should show observations and not hypotheses.

Thematic Subcommissions guide the work of continental Editorial Committees in drafting tectonic, metallogenic, metamorphic, hydrogeologic, and other maps. When scientific progress requires it and as data become available, working groups are formed to conceive new thematic maps, propose legends and make experimental drafts. If the undertaking proves viable and of scientific portent, a Subcommission may be created with corresponding Editorial Committees in each continent.

\section{Map Legends}

The first experimental thematic maps have generally been those of Europe: other continents profit from this experience and adapt the first legend to the information available to them and to regional conditions. The Subcommissions for Tectonic and Metallogenic Maps were created in 1958, that for Metamorphic Maps in 1966. At the request of the International Association of Hydrogeologists (IAH) and the International Association of Scientific Hydrology (IASH), a Subcommission for Hydrogeological Maps was formed in 1966.

The formulation of the content for a new thematic map forces CGMW to study and discuss fundamental observations and theories of earth sciences and to clarify the disparities in terminology in the different languages and different schools of thought. These discussions provide the foundation for a map legend.

Experience has shown that national drafts must be drawn to indicate whether the legend proposed is suited to the entire region to be covered and to the parameters to be illustrated. 
The final general legend is that which appears on the printed map, and several amendments and improvements are normally added to a first 'final' legend in the course of compilation. For the Hydrogeologic Map of Europe, the comparative advantages of three different legends were illustrated by silk screen proofs of one sheet (C5). After discussions, a fourth legend was finally adopted.

Standardized legends may facilitate understanding but rigid adherence to the practice would hinder progress and prevent imaginative improvements required by advances in knowledge. The only world-wide standardized legends are those used on the Geological World Atlas and the World Tectonic Wall Map.

In recent years, CGMW has been asked to promote maps with detailed scales (over 1:1000 000). The Commission views its role in these cases as that of preparing experimental drafts with various trial legends suited to different geological and cultural conditions, and making the results known to interested countries. These thematic maps include those of the environment, engineering geology, and classic hydrogeology.

New legends are required which will show parameters that are keystones for all tectonic theories. One major step forward was made when 'coloured mélange' was admitted to a tectonic map legend, along with the classic terms flysch, molasse and ophiolites. The inclusion of geophysical data on a tectonic map still appears to shock geologists, and is often deemed to be only appropriate on a map of recent tectonics.

\section{Standardization of Scale and Projection}

Standardization of map scale and projection for all thematic maps of a continent is most desirable, and enables rapid correlation between map parameters. The projections selected provide satisfactory area-true representation for as much of the continent or region as possible.

The geographic base maps available are so rarely suited to thematic maps that CGMW has been forced to take an interest in their modification. Commonly the hydrographic network and the place names need to be simplified and geologically important names added. Few continental maps show the essential bathymetry. For example, CGMW added bathymetry to the sheets of the Geological World Atlas, based on the World series 1:5000 000 of the American Geographical Society. In addition, the entire base map for the third edition of the Geological Map of South and East Asia, with bathymetry, was drafted by the Geological Survey of India for CGMW, and bathymetry will be added to the base maps of Africa and South America and according to the fifth series of GEBCO (General Bathymetric Chart of the Oceans) charts.

The variety of projections used for CGMW-sponsored maps is given in Box 1.

\section{World Maps}

In a way, CGMW activity belies its title: to date only two projects are devoted to world maps - the Geological World Atlas, 1:10 000 000, and the World Tectonic Wall Map, $1: 15000000$.

The world-wide Geological World Atlas consists of 16 continental sheets at 1:10000 000 and five oceanic sheets to various scales. The Atlas Committee comprises all CGMW Vice-Presidents, each charged with submitting a draft for their area.

The Convenors of the Geological World Atlas, G. Choubert and A. Faure-Muret, are supported by the Centre National de Recherches Scientifiques (CNRS) in France. The first drafts were prepared under UNESCO contract, but since 1962, apart from a unique grant from the Government of France and an annual grant from IUGS, CGMW itself finances the preparation of the 16 continental sheets. Drafting of the Ocean sheets has been partly supported by the UNESCO Division of Marine Sciences. Publication is in the hands of Mercury Walch of Tasmania, for UNESCO. (Figure 1 shows the layout of the 21 sheets of which the first six were released in 1977: North America (2), Africa (3), and the Pacific Ocean. A further six sheets will be published before the end of 1979.)

The Ocean sheets follow a new concept by showing the age of the oceanic basement, the overlying sediments by isopachs and the unconsolidated deposits removed. The legend carries also shallow, medium and deep focus earthquakes, deep-sea drilling cores, age of basement related to depth of water, and magnetic reversals.

\section{Publication}

Reports on activities, meetings, and recommendations as to legends are published as 'CGMW Bulletins' which appear about twice a year. Also available are lists of National and International Geoscience Maps which give the titles, scales, dates, publishers, and places of sale of all earth science maps on which information has been obtained by the CGMW Secretariat.

For financial reasons, the Commission does not normally participate in the publication of maps. Restricted storage space and manpower preclude the possibility of the Secretariat selling maps.

CGMW generally seeks international funding for the publication of maps that result from international cooperation. Co-publication is often negotiated between a member Survey and an international agency, each providing financial backing. As the maps correspond to some of the interests of UNESCO, particularly in the field of education, some maps are printed by that organization. CGMW recommends that the sale price of its maps be kept as low as possible and to date it has been based on printing costs with no preparation costs being incorporated. Various overhead expenditures, however, are included, and the sale price frequently triples that of printing.

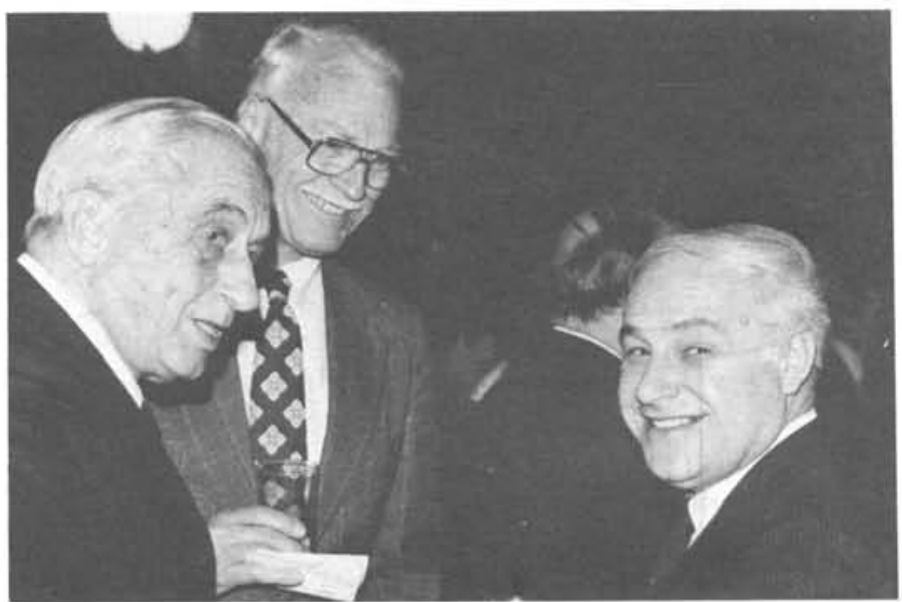

Left to right: Retiring President of CGMW, Jean Marçais (France) discusses the publication of ophiolite maps with Douglas M. Kinney (U.S.A.), Vice President for North America, CGMW, and Nikita A. Bogdanov (U.S.S.R.), Project Leader of IGCP Project 39 "Ophiolites".

\section{Finances}

CGMW is financed from several sources. Annual subscriptions from member countries and associate members are complemented by a grant from the Government of France. Grants from IUGS and contracts signed with international organizations (in particular UNESCO) are normally destined for specific projects or meetings. The Secretary General is on staff at the BRGM-CEGM, while the Presidency is an honorary function.

The annual cost of the Secretariat (some 250,000 FF) is very small compared to the sums provided by participating countries who compile national draft maps or who are responsible for the compilation, clean drawing and printing of 
the continental maps. It is also negligible compared to the costs of printing national and international maps.

The creation of a rotating publication fund, initiated by an outright grant for the first map published, would perhaps alleviate many of CGMW's financial constraints and enable it to fulfil a more effective role.

\section{Meetings}

Plenary sessions are held every second year - during the International Geological Congress and generally in Paris in the inter-Congress biennium. Some 150 delegates report on national mapping, on programmes of the thematic Subcommissions, and then separate into working groups to debate special maps. A major attraction at the plenary sessions is the exhibition of maps, which includes a display of the most recent editions; draft and proof maps are discussed in session.

Continental Subcommissions meet as required, generally in conjunction with international geological conferences. The presentation of maps to conference sessions provides for a wider input to and criticism of the maps, and also serves to advertize CGMW activities.

Itinerant colloquia have been organized to resolve specific problems: international groups of prominent scientists, accompanied by local scientists, have visited critical areas where persisting ambiguities in interpretation or in correlation delayed the regional map compilation. Field studies attended by scientists from neighbouring countries to solve cross-frontier mapping problems have been encouraged.

\section{CGMW's Role: Significance and Future}

Maps published under the aegis of CGMW serve several purposes, both academic and practical. Academic uses are traditional and clear, but their use for development planning (environmental, industrial, urban) demands that certain parameters be stressed to catch the eye of people unaccustomed to 'reading' maps.

CGMW influences national mapping in several ways: it proposes a standard scheme of colours and symbols for maps; by basing continental compilations on national drafts, it promotes national thematic maps; the national Convenor attends Editorial Committee meetings and meets his peers and, as mentioned above, field studies have also been organized under CGMW aegis.

The general scarcity of funds requires that projects be coordinated to prevent duplication of effort, and CGMW's responsibility to participate in such coordination will undoubtedly increase in the future.

To perform its role to best effect over the coming years, CGMW must be able to maintain an active and efficient administrative and scientific network through which the results of the many successful international projects now under way can be cartographically integrated with existing geological knowledge and with each other. Such projects sponsored by inter-governmental or non-governmental organizations include the International Programme of Ocean Drilling (IPOD), the Inter-Union Commission on Geodynamics

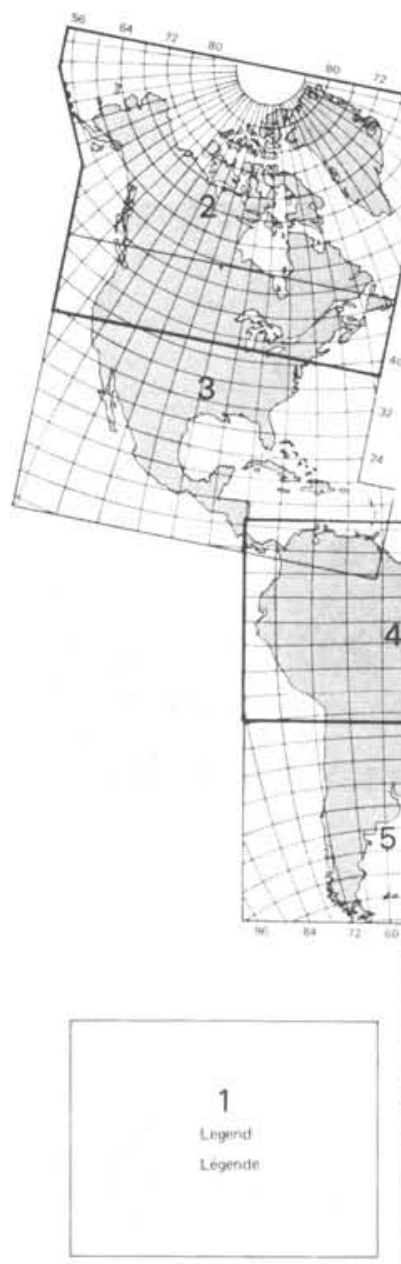

\section{Geological World Atlas}

Scale $1: 10,000,000$

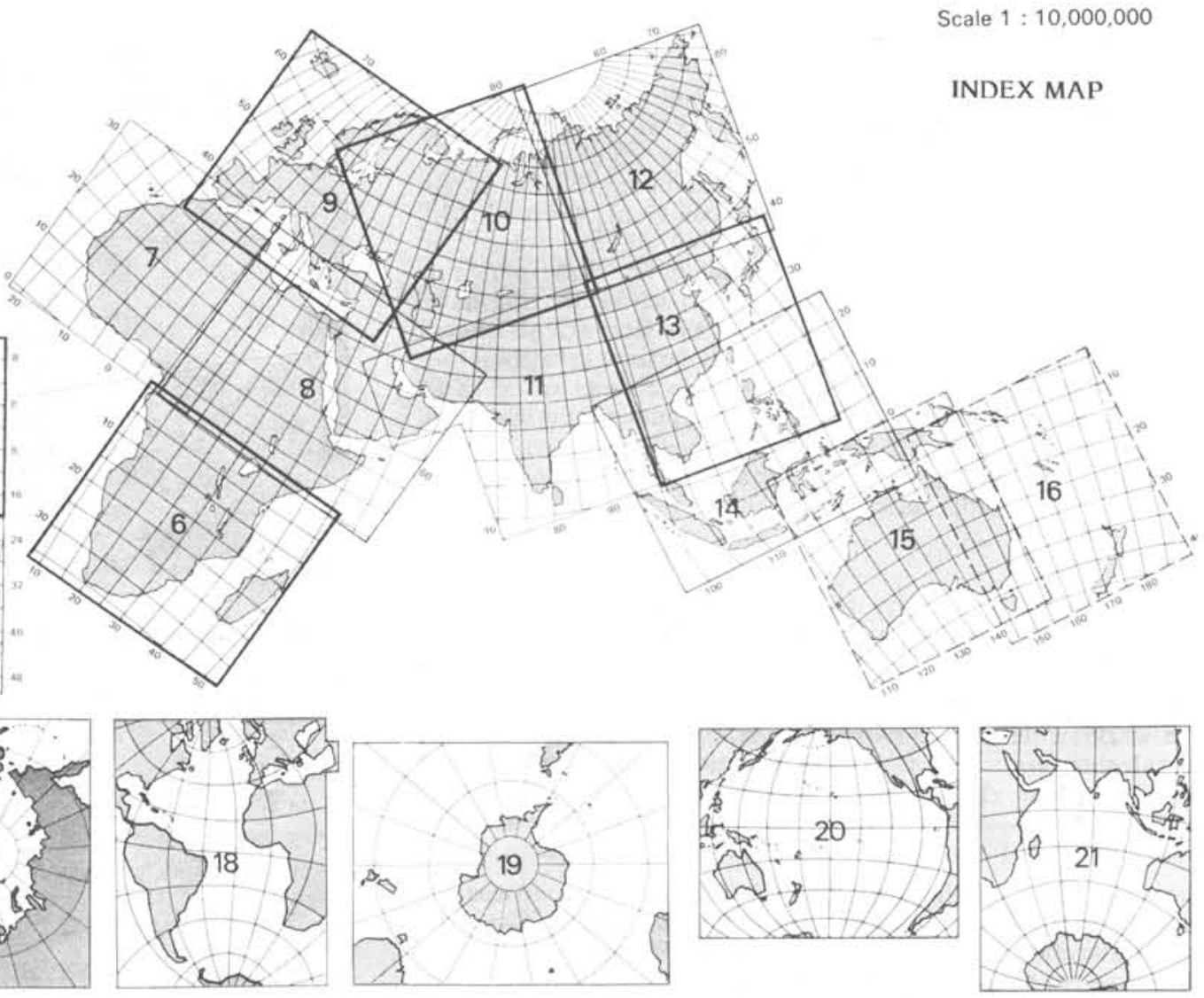

Figure 1: When completed, the Geological World Atlas, 1:10 000 000, together with the explanatory notes on each continent, should provide the first full and up-to-date picture of world geology. Six sheets are currently available from the Unesco Press, 7 Place de Fontenoy, 75700 Paris, France: North America (two sheets), Africa (three sheets), Pacific Ocean (one sheet). 
(ICG), the International Geological Correlation Programme (IGCP), and the International Decade of Ocean Exploration (IDOE). Some data-producing projects could well present their results in map form; others, at their own initiative, could compile maps. In both cases, CGMW can suggest, and often provide, a stable base copy of a suitable geographic base map, propose a meaningful geotectonic background on which thematic results can be plotted, and advise on colours and symbols, drawing and printing techniques.
EDITORS' NOTE: CGMW is collaborating with the USGS in sponsoring a Symposium on Cartography and Printing of Coloured Geological Maps - October 19, 1979 in Reston, Virginia, U.S.A. The Symposium, which is part of the USGS International Centennial Symposium "Resources for the Twenty-First Century" (organized in celebration of the USGS' centennial year), will concentrate on the comparison of modern cartographic and printing techniques. It is planned that a Professional Paper summarizing the outcome of the Symposium will be published within a year.

BOX 1

\section{MAPS PREPARED UNDER THE AEGIS OF THE CGMW}

International Geological Map of Europe and the Mediterranean Region, 1:5 000 000, 1971, 2 sheets, Expl. Not., BfB/UNESCO (Lambert conform conical).

- Carte Tectonique le l'Europe, 1:2 500 000, lère édition, $16 \mathrm{f}$. épuisée, $2 \mathrm{e}$ éd. $20 \mathrm{f}$., sous presse. Com. Réd. Carte Tect. Europe, Univ. de Moscou (Lambert conform conical).

- Carte Métallogénique de l'Europe, 1:2 500 000, dates div., 9 f., légende, Com. Réd. Carte Métal. Europe, BRGM/UNESCO (Lambert conform conical).

- Carte Internationale des Gisements de Fer de l'Europe, 1:2 500 000, dat. div., 16 f., BfB (Lambert conform conical).

- Carte Internationale des Dépôts Houillers, 1:2 500000 , 1968, 16 f., (russe, francais), Acad. Sci., U.R.S.S. (Lambert conform conical).

- Carte Géologique Internationale de l'Europe, 1:1 500 000, dat. div., 3e éd., 49 f., BfB/UNESCO (Lambert conform conical).

- Hydrogeologic Map of Europe, 1:1 500 000, var. dat., Expl. Not., 35 sh., CGMW S/C Hydrogeol. Maps and $\mathrm{AIH}, \mathrm{BfB} / \mathrm{UNESCO}$ (Lambert conform conical).

- Base map of Africa, 1:20 000 000 and 1:10 000000 , 1967, ASGA/UNESCO (Azimuthal Postel Projection, 1936).

- Tectonic Map of Africa, 1:15000000, 1969, CGMW/UNESCO (Azimuthal Postel Projection, 1936).

- Coal Map of Africa, 1:10 000 000, 1966, Expl. Not. R. Feys and J. Fabre, 61 p., ASGA/ECA (Azimuthal Postel Projection, 1936).

- International Geological Map of Africa, 1:5000 000, 2nd ed., 1964, Expl. Not., 39 p., ASGA/UNESCO (Azimuthal Postel Projection, 1936).

- International Tectonic Map of Africa, 1:5000 000, 1968, 9 sh., Expl. Not., 1969, 54 p., ASGA/UNESCO (Azimuthal Postel Projection, 1936).

- Mineral Map of Africa, 1:10 000 000, 1968, Expl. Not., 1969, 18 p., ASGA/UNESCO (Azimuthal Postel Projection, 1936).

- Iron Ore Deposits in Africa, 1:10 000 000, 1970, ASGA (Azimuthal Postel Projection, 1936).

- Metamorphic Map of Africa, 1:10 000 000, 1978, CGMW/UNESCO (Mercator Transverse).

ABOUT THE AUTHOR: A Kenya childhood followed by multilingual education in Switzerland (at Lausanne and the ETH-Zurich) led Frances Delany to field work in Africa (Sudan, Equatorial Africa and Kenya) and, as geologist of the BRGM (Orléans), to Secretary General of the CGMW. She was formerly Secretary General of the Inter-Union Commission on Geodynamics.
- Carte Géologique de l'Afrique, 1:5000 000, in prep., 3 sh. (Mercator Transverse).

- Geological Map of South America, 1:5000 000, 1964, 2 sh., DNPM, Rio (Conform Conical Bipolar Oblique).

- Tectonic Map of South America, 1:5000 000, 1979, 2 sh., DNPM and G.S.A. (Conform Conical Bipolar Oblique).

- Geological Map of Asia and the Far East, 1:5000 000, 1971, 2nd ed., 4 sh., Expl. Not. (English, French), ECAFE/UNESCO (Lambert Conical Orthomorphic).

- Tectonic Map of South and East Asis, 1:5000 000, 7 sh., in press, Conv. D.K. Ray, GSI (Lambert Conical Orthomorphic).

- Geological Map of the World, Australia and Oceania, sh. $2-8,10-12,1: 5000000,1966-68$, BMRGG, Canberra (Lambert Conform Conical Projection).

- Geological Map of the World, Australia and Oceania, sh. 9 and 13, 1:5 000 000, 1966-68, Geol. Surv. N.Z. (Lambert Conform Conical Projection)

- Metallogenic Map of Australia-Oceania, 1:5000 000, in prep., Convenor N.H. Fisher, BMRGG, Canberra (Lambert Conform Conical Projection).

- Geological Map of North America, 1:5 000 000, 1965, 2 sh., USGS (Albers Equal Area Projection).

- Tectonic Map of North America, 1:5000 000, 1969, 2 sh., USGS (Albers Equal Area Projection).

- Geological Map of Antarctica, in prep., CGMW S/C for Antarctica (Polar Projection).

- Tectonic Map of Antarctica, in prep., CGMW S/C for Antarctica (Polar Projection).

- Geological World Atlas, 1:10 000 000, 21 sh., 6 sh. publ. in 1977, 6 in 1979, UNESCO (Miller Oblate Stereographic).

- Tectonic World Map, 1:15 000 000, in prep., V.E. Khain, CGMW S/C Tectonic Maps.

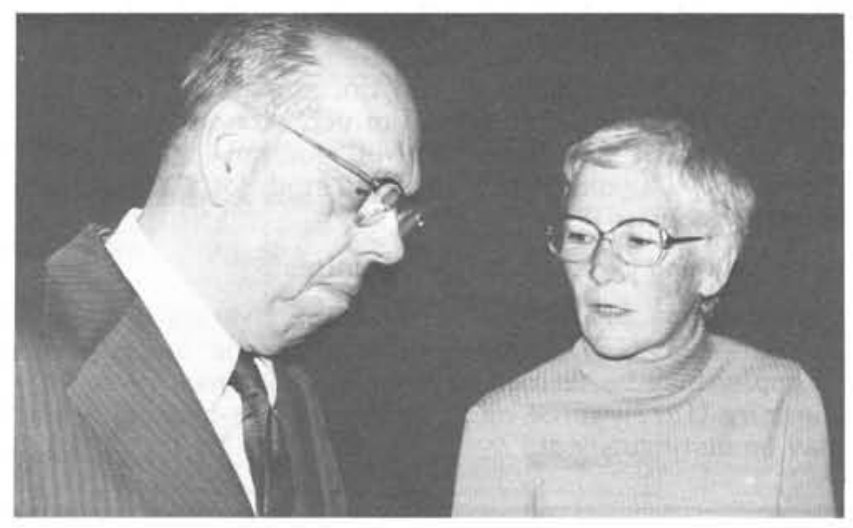

Frances Delany (right) in conversation with the Past President of IUGS, Philip H. Abelson. 